\title{
ANALYTICAL METHOD DEVELOPMENT AND METHOD VALIDATION FOR DETERMINATION ASSAY AND CONTENT UNIFORMITY OF LEVONORGESTREL BY REVERSED-PHASE HIGH- PERFORMANCE LIQUID CHROMATOGRAPHY
}

\author{
VIKAS KUMAR PAL*, YOGENDRA PAL \\ Department of Pharmacy, Pranveer Singh Institute of Technology, Kanpur, Uttar Pradesh, India. Email: vikaskumarpal02@gmail.com \\ Received: 04 January 2020, Revised and Accepted: 13 February 2020
}

\section{ABSTRACT}

Object: The main objective of the complete study is to develop a new method and also to validate the developed method for the determination of Assay and Content Uniformity of Levonorgestrel by reverse-phase high performance liquid chromatography (RP-HPLC).

Methods: RP-HPLC method was developed for simultaneous estimation of levonorgestrel using Hypersil ODS, $125 \mathrm{~mm} \times 4.6 \mathrm{~mm} \times 5 \mu \mathrm{m}$ C8 column with a mixture of water, and acetonitrile solution with a ratio of $50: 50$ as a mobile phase at a flow rate of $1.3 \mathrm{~mL} / \mathrm{min}$ with a detection of quantification wavelength of $242 \mathrm{~nm}$. Method was selected after calculating system suitability and validated as per International Conference on Harmonization (ICH) guidelines.

Results: The developed analytical method parameters found within the limits as given in ICH and USP Guidelines and the total chromatographic analysis time per sample was 8 min with Levonorgestrel Eluting with retention time of 4.479, 4.479, and 4.467 min, respectively. The validated HPLC method was successfully applied for the determination of dissolution of levonorgestrel tablets.

Conclusion: The method is simple, precise, specific, and accurate. The newly developed method can be used for routine analysis of Levonorgestrel in tablet dosage form.

Keywords: Method development, Method validation, Levonorgestrel, Reversed-phase high-performance liquid chromatography.

(c) 2020 The Authors. Published by Innovare Academic Sciences Pvt Ltd. This is an open access article under the CC BY license (http://creativecommons. org/licenses/by/4. 0/) DOI: http://dx.doi.org/10.22159/ajpcr.2020.v13i4.36771

\section{INTRODUCTION}

Levonorgestrel is $13 \beta$-ethyl-17 $\beta$-hydroxy-18, 19-dinor-17 $\alpha$ - pregn-4en-20-yn3-one (Fig. 1) as oral contraceptive pills obtained in combined monophasic or multiphasic forms [1-3].

Levonorgestrel or l-norgestrel or d-norgestrel belongs to the secondgeneration synthetic progestogen, used both as an effective, safe, and emergency contraception, as well as an alternative or a combination of hormonal replacement therapy. It is examined in pharmacokinetics studies of orally administered levonorgestrel that it bypasses the first metabolism are well-explored but in women, it reveals substantial variation in their levonorgestrel serum concentrations. As a result, there is an increment of 1.6 -fold from the $25^{\text {th }}$ to $75^{\text {th }}$ percentile level in levonorgestrel concentration [4-7]. When the activity of estrogen and progestin is combined, it inhibits ovulation and attains contraception. In addition to the contraception, the recent advances in oral contraceptives attracted to obtaining new formulation with further benefits and fewer side effects [8]. The effective and convenient oral male contraceptives are not yet available in the market. While levonorgestrel as female oral contraceptive drug is available commercially by different trade names, including Escapelle (levonorgestrel), Levonelle (levonorgestrel), Glanique (levonorgestrel), NorLevo (levonorgestrel), i-pill (levonorgestrel), Next Choice (levonorgestrel), Altravera (levonorgestrel and Ethinyl Estradiol), Brevicon (Norethindrone and Ethinyl Estradiol), and Levora (Levonorgestrel and Ethinyl Estradiol)[9]. To determine the quantitative and qualitative composition of the material, analytical chemistry is used. To understand the sample materials, both these aspects are necessary. When there is no analytical method is available in any Pharmacopoeia or any other literature for the new product, then the new analytical methods are developed. The main objective of an alternate method for existing (non-pharmacopeial) products is for better precision and ruggedness, cost-effective, and reduces time. When the proposed alternate method is expected to replace the already existing procedure then the comparative laboratory date should be provided, including merits and demerits. The aim of the high-performance liquid chromatography (HPLC)-method is to isolate and quantify the active drug, any reactive impurities, synthetic intermediates, and degradants. Steps involved in method development are as understanding the physiochemical properties of drug molecules, selection of chromatographic situation, developing the approach of analysis, sample preparation, method optimization, and method validation $[10,11]$. Validation of an analytical method is the process in which the performance characteristics of the method meet the requirement for the intended analytical application, proposed by laboratory studies. Validation is required for any new or amended method to ensure that it provides reproducible and reliable results, whenever is used by employing the same equipment in the same or different laboratories. The selection of the type of validation program depends on the particular method and its proposed applications and the results obtained can be used to assure the quality, reliability, and consistency of analytical results which are an elemental part of the acceptable analytical practice. In the method of the validation process, the equipment used should be within specification, operative, and adequately calibrated. Analytical methods need to be validated or

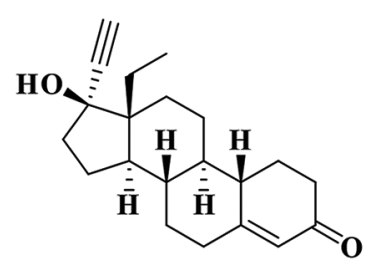

13b-ethyl-17b-hydroxy-18,19-dinor-17a-pregn-4- en-20-yn-3-one

Fig. 1: Levonorgestrel 


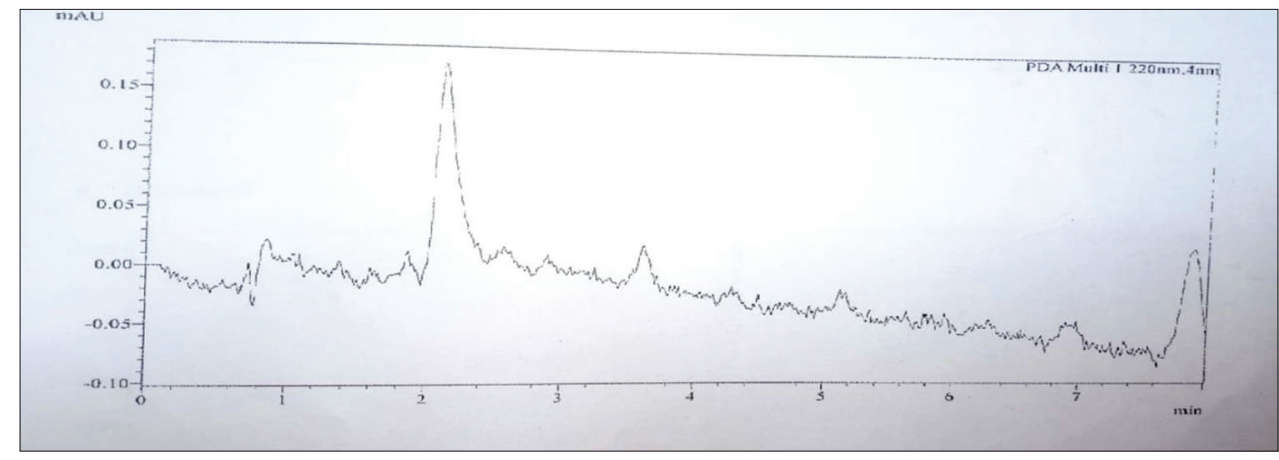

Fig. 2: Chromatogram of blank solution

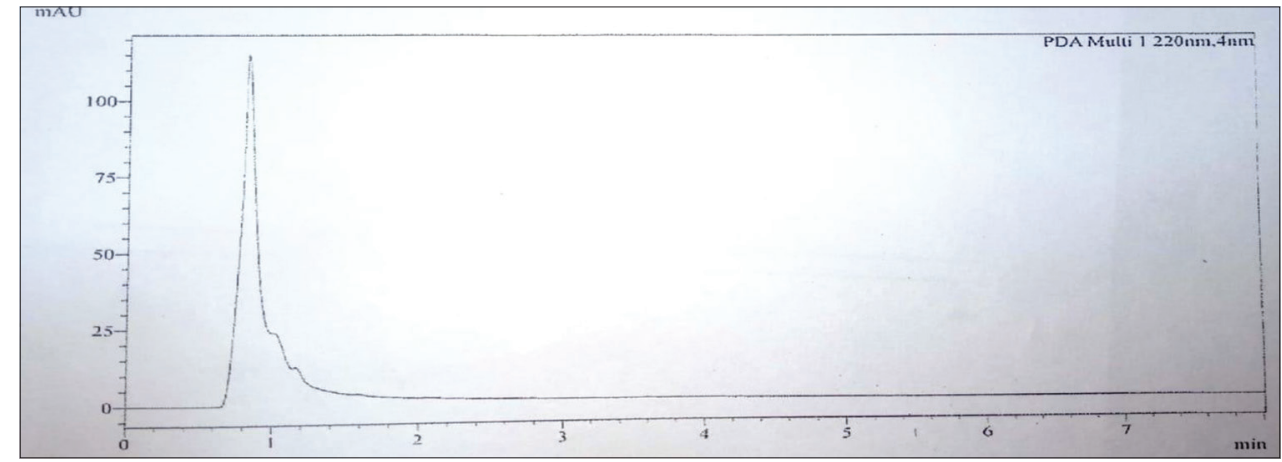

Fig. 3: Chromatogram of placebo

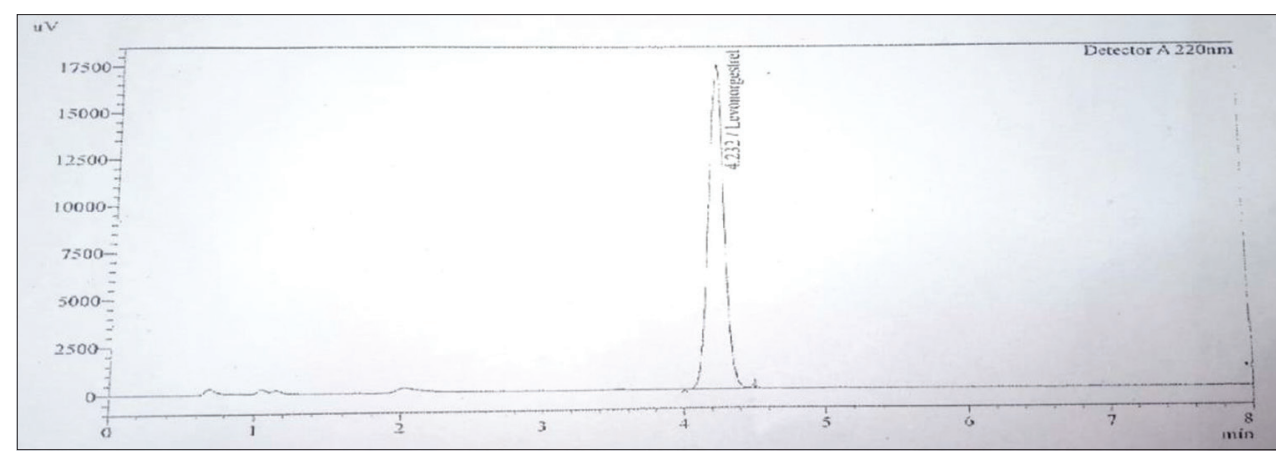

Fig. 4: Chromatogram of standard solution

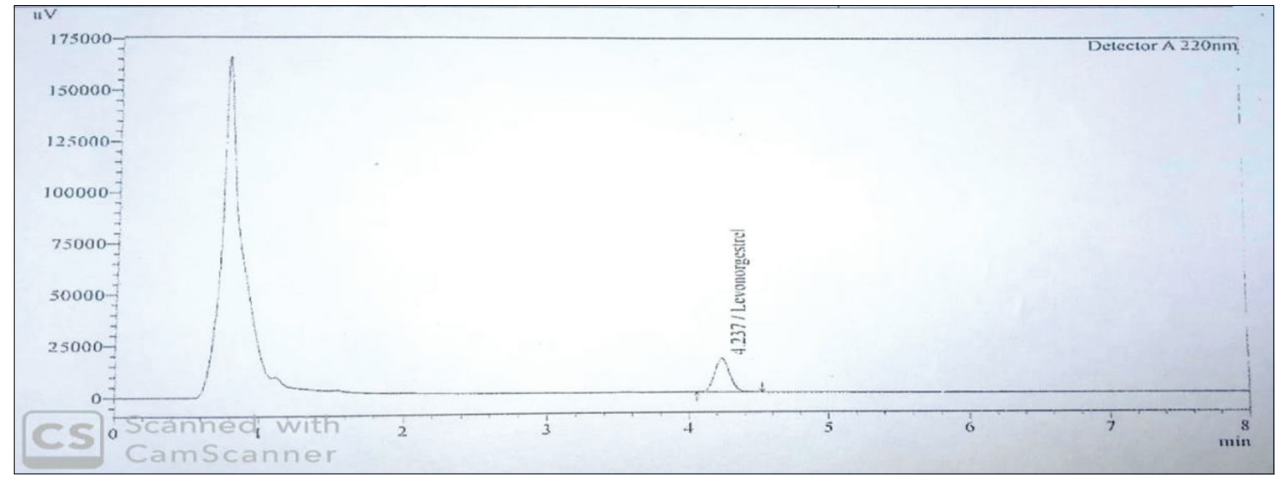

Fig. 5: Chromatogram of sample solution

revalidated before their introduction into routine use, whenever the conditions change for the method should be validated or whenever the methods changed typical parameters recommended by USP, FDA, and International Conference on Harmonization (ICH) are as specificity, linearity, and range, precision, accuracy (recovery), solution stability, limit of detection, limit of quantification, robustness and system suitability. Analytical method development and validation play important roles in the discovery development and manufacture of pharmaceuticals. These methods are used to ensure the identity, purity, potency, and performance of drug products [12-14]. 


\section{METHODS}

\section{Standards and reagents}

Levonorgestrel sample; $13 \beta$-ethyl-17 $\beta$-hydroxy-18, and 19-dinor-17 $\alpha$ pregn-4-en-20-yn3-one were obtained from in-house R\&D Centre of Naari Pharma Rudrapur. The sample was well characterized by infrared spectroscopy, mass spectroscopy, proton nuclear magnetic resonance spectroscopy, and carbon nuclear magnetic resonance spectroscopy.

Potassium dihydrogen orthophosphate, glacial acetic acid, sodium acetate trihydrate, and hydrochloric acid of AR grade were obtained from Fischer Scientific Chemicals. Sodium hydroxide was obtained from Merck Chemicals. Acetonitrile and methanol of HPLC grade were obtained from Merck Chemicals. Water was used from a Milli-Q water purification system.

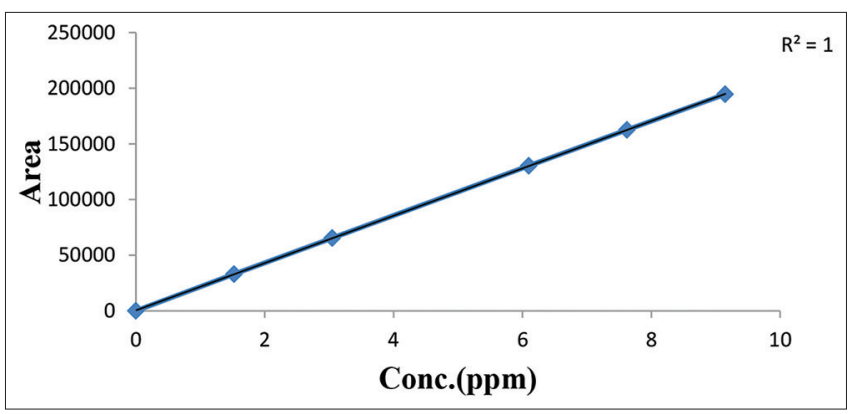

Fig. 6: Linearity curve

Table 1: Retention time and peak purity

\begin{tabular}{lll}
\hline Name of sample & $\begin{array}{l}\text { Retention time } \\
\text { (minutes) }\end{array}$ & Peak purity index \\
\hline Standard solution & 4.278 & 1.000000 \\
Sample solution & 4.276 & 1.000000 \\
Spiked sample solution & 4.274 & 1.000000 \\
\hline
\end{tabular}

\section{Instrumentation and software}

The analytical method development and validation were performed on HPLC (Make \& Model: Shimadzu LC-2030C Prominence-i with PDA Detector and Shimadzu LC-2010CHT) equipped with a quaternary solvent delivery pump, degasser, auto-sampler, and column thermostat using lab solution for method development and Empower Software for method validation. Chromatographic separation on Hypersil ODS C18 column (Size: $125 \mathrm{~mm} \times 4.6 \mathrm{~mm} ; 5 \mu$ particle size) using a gradient program at a flow rate of $1.3 \mathrm{~mL} / \mathrm{min}$ and an injection volume of $200 \mu \mathrm{L}$ with wavelength detection at $242 \mathrm{~nm}$. The mobile phase consists of water and acetonitrile (500:500, v/v).

\section{Preparation of solution}

Mobile phase: Prepared a mixture of acetonitrile and water in the ratio of 50:50 v/v, respectively, sonicated for $15 \mathrm{~min}$ to remove the gas impurity.

Diluent: Mixed acetonitrile and water in the ratio of 50:50 v/v, respectively, sonicated for 15 min to remove the gases impurity.

Preparation of control standard solution: Weighed accurately $24.96 \mathrm{mg}$ of levonorgestrel working standard and transfer into a $200 \mathrm{ml}$ volumetric flask, and then added $160 \mathrm{~mL}$ of diluents, sonicated to dissolve and made up the volume with diluents and mixed well. Pipette out of $5 \mathrm{~mL}$ of this stock solution into a $100 \mathrm{~mL}$ volumetric flask and made up the volume with diluents and mixed well.

\section{For assay}

Preparation of standard solution: Weighed accurately $24 \mathrm{mg}$ of levonorgestrel working standard and transfer into a $200 \mathrm{ml}$ volumetric flask, and then added $160 \mathrm{~mL}$ of diluents, sonicated to dissolve and made up the volume with diluents and mixed well. Pipette out of $5 \mathrm{~mL}$ of this stock solution into a $100 \mathrm{~mL}$ volumetric flask and made up the volume with diluents and mixed well.

Preparation of sample solution: Weighed and transferred 20 intact tablets into $100 \mathrm{~mL}$ volumetric flask, added $60 \mathrm{~mL}$ of diluent, sonicated

Table 2: Preparation of linearity solutions

\begin{tabular}{llllll}
\hline Sr. No. & Level $(\%)$ & Dilution $(\mathbf{m L})$ & Final volume with diluent $(\mathbf{m L})$ & Concentration $(\boldsymbol{\mu g} / \mathbf{m L})$ levonorgestrel & Area \\
\hline 1. & 25 & 1.0 & 100 & 1.52445 & 33,045 \\
2. & 50 & 2.0 & 100 & 3.04889 & 65,414 \\
3. & 100 & 4.0 & 100 & 6.09889 & 130,296 \\
4. & 125 & 5.0 & 100 & 7.62223 & 162,364 \\
5. & 150 & 100 & 9.14667 & 194,663 \\
Slope & & & & $21,220.76$ \\
Intercept & & & & 750.79 \\
Correlation coefficient & & & & 1.000 \\
\% Y intercept & & & & 0.576 \\
\hline
\end{tabular}

Table 3: Preparation of accuracy solutions

\begin{tabular}{|c|c|c|c|c|c|c|c|}
\hline Sr. No. & Recovery level (\%) & Amount added (mg) & Actual found (mg) & Recovery (\%) & Mean (\%) & SD & $\% \operatorname{RSD}(n=3)$ \\
\hline \multirow[t]{3}{*}{1.} & 50 & 0.3037912 & 0.3091186 & 101.8 & 101.5 & 0.3000 & 0.30 \\
\hline & & 0.3037912 & 0.3082218 & 101.5 & & & \\
\hline & & 0.3037912 & 0.3072993 & 101.2 & & & \\
\hline \multirow[t]{3}{*}{2.} & 100 & 0.6075824 & 0.6090802 & 100.2 & 101.0 & 0.6807 & 0.67 \\
\hline & & 0.6075824 & 0.6151670 & 101.2 & & & \\
\hline & & 0.6075824 & 0.6168955 & 101.2 & & & \\
\hline \multirow[t]{3}{*}{3.} & 150 & 0.9113736 & 0.9208894 & 101.0 & 101.1 & 0.1155 & 0.11 \\
\hline & & 0.9113736 & 0.9204910 & 101.0 & & & \\
\hline & & 0.9113736 & 0.9221193 & 101.2 & & & \\
\hline \multicolumn{2}{|c|}{ Overall mean $(n=9)$} & & & 101.2 & & & \\
\hline \multicolumn{2}{|c|}{ Overall SD $(n=9)$} & & & 0.4494 & & & \\
\hline \multicolumn{2}{|c|}{ Overall RSD ( $\mathrm{n}=9$ ) } & & & 0.44 & & & \\
\hline
\end{tabular}

SD: Standard deviation, RSD: Relative standard deviation 
Table 4: System precision

\begin{tabular}{ll}
\hline S. No. & Peak area counts of levonorgestrel \\
\hline 1. & 130,335 \\
2. & 130,350 \\
3. & 130,374 \\
4. & 130,398 \\
5. & 130,445 \\
6. & 130,579 \\
Mean & 130,413 \\
\% RSD & 0.069 \\
\hline
\end{tabular}

Table 5: Method precision for assay

\begin{tabular}{lll}
\hline Sr. No. & Sample & \% Assay \\
\hline 1. & Preparaton_1 & 97.1 \\
2. & Preparaton_2 & 97.3 \\
3. & Preparaton_3 & 97.2 \\
4. & Preparaton_4 & 97.5 \\
5. & Preparaton_5 & 97.4 \\
6. & Preparaton_6 & 97.3 \\
Mean & & 97.3 \\
\% RSD & & 0.15 \\
\hline
\end{tabular}

Table 6: Method precision for content uniformity

\begin{tabular}{lll}
\hline S. No. & Sample & \% Assay \\
\hline 1. & Preparation_1 & 99.9 \\
2. & Preparation_2 & 99.7 \\
3. & Preparation_3 & 99.5 \\
4. & Preparaton_4 & 101.0 \\
5. & Preparation_5 & 101.3 \\
6. & Preparation_6 & 101.4 \\
7. & Preparaton_7 & 98.5 \\
8. & Preparation_8 & 97.9 \\
9. & Preparation_9 & 100.3 \\
10. & Preparation_10 & 102.5 \\
Mean & & 100.2 \\
\% RSD & & 1.40 \\
\hline
\end{tabular}

RSD: Relative standard deviation

Table 7: Extraction efficiency

\begin{tabular}{llll}
\hline \multirow{2}{*}{ S. No. } & \multicolumn{2}{l}{ Assay (\%) of levonorgestrel } \\
\cline { 2 - 4 } & Method precision & $\mathbf{4 0}$ min sonication & $\mathbf{5 0}$ min sonication \\
\hline 1. & 97.1 & 97.5 & 99.4 \\
2. & 97.3 & 98.4 & 97.6 \\
3. & 97.2 & 97.9 & 97.9 \\
4. & 97.5 & NA & \\
5. & 97.4 & & \\
6. & 97.3 & 97.9 & 98.4 \\
Mean (n=3) & 0.46 & 1.10 \\
\%RSD (n=3) & 98.0 & 98.0 \\
Overall mean (n=9) & 0.41 & 0.72 \\
\multicolumn{2}{l}{ Overall \% RSD (n=9) }
\end{tabular}

SD: Standard deviation, RSD: Relative standard deviation

for 45 min with intermittent shaking and made up the volume with diluents. Filtered the solution with a $0.45 \mu \mathrm{m}$ polyvinylidene fluoride (PVDF) filter, discarding the first $3 \mathrm{~mL}$ of filtrate and injected the clear solution.

\section{For content uniformity}

Preparation of standard solution: Weighed accurately $24 \mathrm{mg}$ of levonorgestrel working standard and transferred into a $200 \mathrm{ml}$
Table 8: Variable conditions of robustness

\begin{tabular}{lll}
\hline Robustness condition & Altered condition & Variation \\
\hline Temperature & -Temperature & $20^{\circ} \mathrm{C}$ \\
& +Temperature & $30^{\circ} \mathrm{C}$ \\
Flow & -Flow & $1.15 \mathrm{~mL} / \mathrm{min}$ \\
\multirow{3}{*}{ Wavelength } & +Flow & $1.45 \mathrm{~mL} / \mathrm{min}$ \\
& -Wavelength & $218 \mathrm{~nm}$ \\
Mobile phase composition & +Wavelength & $222 \mathrm{~nm}$ \\
& -Organic & $40 \%$ Acetonitrile \\
& +Organic & $60 \%$ Acetonitrile \\
\hline
\end{tabular}

Table 9: Robustness for column temperature

\begin{tabular}{|c|c|c|c|}
\hline \multirow[t]{2}{*}{ Sr. No. } & \multicolumn{3}{|c|}{ Assay (\%) of levonorgestrel } \\
\hline & Method precision & +Temperature & -Temperature \\
\hline 1. & 97.1 & 98.1 & 98.1 \\
\hline 2. & 97.3 & 98.0 & 98.2 \\
\hline 3. & 97.2 & 97.7 & 97.4 \\
\hline 4. & 97.5 & NA & \\
\hline 5. & 97.4 & & \\
\hline 6. & 97.3 & & \\
\hline \multicolumn{2}{|c|}{ Mean $(n=3)$} & 97.9 & 97.9 \\
\hline \multicolumn{2}{|c|}{$\% \operatorname{RSD}(n=3)$} & 0.21 & 0.45 \\
\hline \multicolumn{2}{|c|}{ Overall mean $(n=9)$} & 98.0 & 98.0 \\
\hline \multicolumn{2}{|c|}{ Overall \%RSD $(n=9)$} & 0.36 & 0.40 \\
\hline
\end{tabular}

SD: Standard deviation, RSD: Relative standard deviation

Table 10: Robustness for flow rate

\begin{tabular}{llll}
\hline \multirow{2}{*}{ S. No. } & \multicolumn{2}{l}{ Assay (\%) of levonorgestrel } \\
\cline { 2 - 4 } & Method precision & +Flow rate & -Flow rate \\
\hline 1. & 97.1 & 99.4 & 99.7 \\
2. & 97.3 & 100.2 & 100.7 \\
3. & 97.2 & 97.9 & 97.9 \\
4. & 97.5 & NA & \\
5. & 97.4 & & \\
6. & 97.3 & 99.2 & \\
Mean (n=3) & & 1.18 & 99.4 \\
\%RSD (n=3) & 98.0 & 1.43 \\
Overall mean (n=9) & 1.13 & 98.0 \\
Overall \%RSD (n=9) & & 1.31 \\
\hline
\end{tabular}

SD: Standard deviation, RSD: Relative standard deviation

volumetric flask, then added $160 \mathrm{~mL}$ of diluents, sonicated to dissolve and made up the volume with diluents and mixed well. Pipette out of $5 \mathrm{~mL}$ of this stock solution into a $100 \mathrm{~mL}$ volumetric flask and made up the volume with diluents and mixed well.

Sample preparation for levonorgestrel tablet: Selected not fewer than 30 dosage units and perform 10 tablets individually as follow:

Transferred 1 tablet into $5 \mathrm{~mL}$ volumetric flask, added $3 \mathrm{~mL}$ of diluents, sonicated for 45 min with occasional shaking and made up the volume with diluents. Filtered the solution with $0.45 \mu \mathrm{m}$ PVDF filter, discarding the first $3 \mathrm{~mL}$ of filtrate and injected the clear solution.

\section{Analytical method development}

We had selected a mixture of acetonitrile and water in the ratio of $50: 50, \mathrm{v} / \mathrm{v}$, respectively, sonicated them for $15 \mathrm{~min}$ to remove the gasses impurity. And column was used Hypersil ODS (125 mm×4.6 mm, $5 \mu \mathrm{m}$ ), injection volume $25 \mu \mathrm{l}$ with a flow rate of $1.3 \mathrm{~mL} / \mathrm{min}$ at a wavelength of $220 \mathrm{~nm}$.

\section{Analytical method validation}

According to the ICH guidelines Q2 (R1), the analytical method shall be validated by including all analytes (levonorgestrel) by considering 
Table 11: Robustness for wavelength

\begin{tabular}{llll}
\hline \multirow{2}{*}{ S. No. } & \multicolumn{2}{l}{ Assay (\%) of levonorgestrel } \\
\cline { 2 - 4 } & Method precision & +Wavelength & -Wavelength \\
\hline 1. & 97.1 & 98.3 & 98.6 \\
2. & 97.3 & 98.7 & 99.0 \\
3. & 97.2 & 97.5 & 97.3 \\
4. & 97.5 & NA & \\
5. & 97.4 & & \\
6. & 97.3 & 98.2 & \\
Mean (n=3) & & 0.62 & 0.90 \\
\%RSD (n=3) & & 98.0 & 98.0 \\
Overall mean (n=9) & 0.55 & 0.69 \\
Overall \%RSD (n=9) & & \\
\hline
\end{tabular}

SD: Standard deviation, RSD: Relative standard deviation

Table 12: Robustness for mobile phase concentration

\begin{tabular}{llll}
\hline \multirow{2}{*}{ Sr. No. } & \multicolumn{2}{l}{ Assay (\%) of levonorgestrel } & \\
\cline { 2 - 4 } & Method precision & +Organic & -Organic \\
\hline 1. & 97.1 & 99.6 & 99.8 \\
2. & 97.3 & 100.9 & 101.1 \\
3. & 97.2 & 97.0 & 97.5 \\
4. & NA & \\
5. & & \\
6. & 97.5 & & \\
Mean (n=3) & 97.4 & 99.2 & 99.5 \\
\% RSD (n=3) & & 2.00 & 1.83 \\
Overall mean (n=9) & 98.0 & 98.0 \\
Overall \% RSD (n=9) & 1.40 & 1.45 \\
\hline
\end{tabular}

SD: Standard deviation, RSD: Relative standard deviation

the parameters such as specificity, linearity, accuracy (recovery), and precision, robustness, stability of analytical solution, media degassing effect, and filter study.

\section{Specificity}

i. Identification: Standard and sample have been prepared as per methodology and compared the retention times of levonorgestrel peak in standard and sample solution

ii. Interference study: Blank (diluent), standard solution, placebo, sample solution, and spiked sample solution have been prepared and injected into the HPLC equipped with a photodiode array detector and analyzed as per methodology.

\section{Linearity}

Prepared a series of linearity solutions by quantitatively diluting the stock solution of Levonorgestrel working standards to obtained solutions in the range of $25-150 \%$ of the working concentration. Injected each solution and calculate the mean area.

Preparation of levonorgestrel stock solution for linearity: Weighed accurately $30.55 \mathrm{mg}$ of levonorgestrel working standard and transferred into a $200 \mathrm{~mL}$ volumetric flask, then added $160 \mathrm{~mL}$ of diluent sonicate to dissolve and made up the volume with diluent and mixed well.

\section{Accuracy}

The accuracy of an analytical procedure expresses the closeness of agreement between the value which is accepted either as a conventional true value or an accepted reference value and the value found.

\section{Precision}

i. System precision: Six replicate injection of the standard solution was injected into the HPLC system as per proposed methodology

ii. Method precision (repeatability) for assay: Six sample solutions levonorgestrel of levonorgestrel tablet were prepared and analyzed as per methodology
Table 13: Stability of analytical solution

\begin{tabular}{|c|c|c|c|c|c|}
\hline \multirow{2}{*}{$\begin{array}{l}\text { Time } \\
\text { (h) }\end{array}$} & \multicolumn{2}{|c|}{ Standard } & \multirow{2}{*}{$\begin{array}{l}\text { Time } \\
\text { (h) }\end{array}$} & \multicolumn{2}{|l|}{ Sample } \\
\hline & Area & $\%$ Difference & & Area & $\%$ Difference \\
\hline Initial & 127,238 & 0 & Initial & 123,186 & 0 \\
\hline $2 \mathrm{~h}$ & 127,992 & -0.59 & $2 \mathrm{~h}$ & 123,320 & -0.11 \\
\hline $3 \mathrm{~h}$ & 128,366 & -0.89 & $3 \mathrm{~h}$ & 123,737 & -0.45 \\
\hline $6 \mathrm{~h}$ & 128,740 & -1.18 & $6 \mathrm{~h}$ & 124,228 & -0.85 \\
\hline $12 \mathrm{~h}$ & 130,255 & -2.37 & $12 \mathrm{~h}$ & 126,411 & -2.62 \\
\hline $19 \mathrm{~h}$ & 131,738 & -3.54 & $19 \mathrm{~h}$ & 128,487 & -4.30 \\
\hline
\end{tabular}

iii. Method precision (repeatability) for the content of uniformity: Ten sample solutions of levonorgestrel tablet were prepared and analyzed as per methodology.

\section{Filter study}

Prepared the blank and standard solution as per proposed methodology for partial validation. The assay was carried on three sets of levonorgestrel tablets mg from a single lot as per proposed methodology for partial validation and analyzed by making the following small deliberate variations in the sample preparation.

a. Filtered the solution with a $0.45 \mu \mathrm{m}$ Nylon filter discarding the first $5 \mathrm{~mL}$ of the filtrate and injected the clear solution

b. Filtered the solution with a $0.45 \mu \mathrm{m}$ PTFE filter discarding the first $5 \mathrm{~mL}$ of the filtrate and injected the clear solution.

\section{Extraction efficiency}

Prepared the blank and standard solution as per proposed methodology for partial validation. The assay was carried on three sets of levonorgestrel tablets from a single lot as per proposed methodology for partial validation and analyzed by making the following small deliberate variations in the sample preparation.

a. Sonicated the solution for $40 \mathrm{~min}$ with intermittent shaking and filtered with a $0.45 \mu \mathrm{m}$ PVDF filter discarding the first $5 \mathrm{~mL}$ of the filtrate and injected the clear solution

b. Sonicated the solution for $50 \mathrm{~min}$ with intermittent shaking and filtered with a $0.45 \mu \mathrm{m}$ PVDF filter discarding the first $5 \mathrm{~mL}$ of the filtrate and injected the clear solution.

\section{Robustness}

Robustness was carried in three sample solution of levonorgestrel tablets form a single lot as per proposed methodology for partial validation and analyzed by making the following small deliberate variations in the chromatographic conditions.

a. Change in the temperature by $\pm 5^{\circ} \mathrm{C}$ of $25^{\circ} \mathrm{C}$ (i.e. $20^{\circ} \mathrm{C}$ and $30^{\circ} \mathrm{C}$ )

b. Change in the flow rate by $\pm 015 \mathrm{~mL} / \mathrm{min}$ of $1.3 \mathrm{~mL} / \mathrm{min}$ (i.e., $1.15 \mathrm{~mL} / \mathrm{min}$ and $1.45 \mathrm{~mL} / \mathrm{min}$ )

c. Change in the wavelength by $\pm 2 \mathrm{~nm}$ of $220 \mathrm{~nm}$ (i.e., $218 \mathrm{~nm}$ and $222 \mathrm{~nm}$ )

d. Change in the mobile phase composition $\pm 10 \%$ (i.e., water:acetonitrile [40:60 v/v] and water:acetonitrile [60:40]).

\section{Stability of analytical solution}

Stability of analytical solution was verified by analyzing standard solution and sample solution at different time intervals by storing then at room temperature.

\section{RESULTS AND DISCUSSION}

\section{Analytical method development}

It was observed that the solution remains milky after centrifuge but the sample was clear with filter. The \%RSD of the standard solution was found that $0.13 \%$ and $\%$ assay of sample solution was found within limit. The chromatogram of blank solution, placebo, standard solution, and sample solution is shown in Figs. 2-5, respectively. 


\section{Analytical method validation}

Specificity

\section{i. Identification}

Observation: The retention time of the peak of levonorgestrel obtained in the sample solution corresponds to that obtained in the standard solution.

ii. Interference study

Observation: There is no interference observed at the retention time of levonorgestrel peak due to blank, placebo and all known impurities peaks. Peak purity for levonorgestrel peak in standard solution, sample solution, and spiked sample solution has been checked and found passed. The results are given in Table 1.

Conclusion: The method meets the acceptance criteria for specificity. Hence, the method is specific with respect to the retention time of levonorgestrel.

\section{Linearity}

Prepare a series of linearity solutions by quantitatively diluting the stock solution of levonorgestrel working standards to obtained solutions in the range of $25-150 \%$ of the working concentration. Inject each solution and calculate the mean area. The results are given in Table 2 and the linearity curve plotted is shown in Fig. 6

Observation: The correlation coefficient was within limit; hence, method is linear from $25 \%$ to $150 \%$ of the target concentration of the levonorgestrel.

Conclusion: The method meets the acceptance criteria for linearity. Hence, the method is linear for the determination of assay of levonorgestrel over above-mentioned range.

\section{Accuracy}

The accuracy of an analytical procedure expresses the closeness of agreement between the value which is accepted either as a conventional true value or an accepted reference value and the value found. The results are given in Table 3.

Observation: Based on the above accuracy data, it is proved that the analytical method is accurate at above three different accuracy levels.

Conclusion: The analytical method meets the acceptance criteria for the recovery study. Hence, the method is accurate with precision.

\section{Precision}

System precision: Six replicate injection of the standard solution was injected into the HPLC system as per the proposed methodology. Results are given in Table 4.

Observation: Percentage relative standard deviation (RSD) of six replicate injections of standard solution was within limit.

Method precision (repeatability) for assay: Six sample solutions levonorgestrel of levonorgestrel tablet were prepared and analyzed as per methodology. Results are given in Table 5.

Method precision (repeatability) for the content of uniformity: Ten sample solutions of levonorgestrel tablet were prepared and analyzed as per methodology. The results are given in Table 6 .

Observation: \%RSD of six preparation of assay and ten sample preparation of content uniformity were within limit. Hence, the method is precise.

Conclusion: Analytical method meets the acceptance criteria for method precision. Hence, the method is precise.

\section{Extraction efficiency}

Prepare the blank and standard solution as per proposed methodology for partial validation. The assay was carried on three sets of levonorgestrel tablets $0.03 \mathrm{mg}$ from a single lot as per proposed methodology for partial validation and analyzed by making the following small deliberate variations in the sample preparation. Results are given in Table 7.

a. Sonicate the solution for 40 min with intermittent shaking and filtered with a $0.45 \mu \mathrm{m}$ PVDF filter discarding the first $5 \mathrm{~mL}$ of the filtrate and inject the clear solution

b. Sonicate the solution for 50 min with intermittent shaking and filtered with a $0.45 \mu \mathrm{m}$ PVDF filter discarding the first $5 \mathrm{~mL}$ of the filtrate and inject the clear solution.

Observation: The percent assay $(n=3)$ of levonorgestrel of three sets was found to meet the specification. \%RSD $(n=3)$ for percent assay of levonorgestrel of three sets was found within acceptance criteria. Overall, \%RSD ( $\mathrm{n}=9)$ for percent assay of levonorgestrel in method precision each extraction condition was found within acceptance criteria

Conclusion: The method meets the acceptance criteria for extraction efficiency (increase and decrease sonication time).

\section{Robustness}

Robustness was carried in three sample solution of levonorgestrel tablets $0.03 \mathrm{mg}$ form a single lot as per proposed methodology for partial validation and analyzed by making the following small deliberate variations in the chromatographic conditions, as shown in Table 8. Results are given in Tables 9-12.

a. Change in the temperature by $\pm 5^{\circ} \mathrm{C}$ of $25^{\circ} \mathrm{C}$ (i.e., $20^{\circ} \mathrm{C}$ and $30^{\circ} \mathrm{C}$ )

b. Change in the flow rate by $\pm 015 \mathrm{~mL} / \mathrm{min}$ of $1.3 \mathrm{~mL} / \mathrm{min}$ (i.e., $1.15 \mathrm{~mL} / \mathrm{min}$ and $1.45 \mathrm{~mL} / \mathrm{min}$ )

c. Change in the wavelength by $\pm 2 \mathrm{~nm}$ of $220 \mathrm{~nm}$ (i.e., $218 \mathrm{~nm}$ and $222 \mathrm{~nm}$ )

d. Change in the mobile phase composition $\pm 10 \%$ (i.e., water:acetonitrile $[40: 60 \mathrm{v} / \mathrm{v}]$ and water:acetonitrile [60:40]).

Observation: The percent assay $(n=3)$ of levonorgestrel of three sample solutions was found to meet the specification. $\%$ RSD $(n=3)$ for percent assay of levonorgestrel of three sample solution was found within acceptance criteria. Overall, \%RSD (n=9) for percent assay of levonorgestrel in method precision and each robustness parameter was found within acceptance criteria.

Conclusion: The method is robust regarding the change in column temperature (by $\pm 5^{\circ} \mathrm{C}$ ), change in the flow rate of mobile phase (by $\pm 0.15 \mathrm{~mL} / \mathrm{min}$ ), change in wavelength (by $\pm 2 \mathrm{~nm}$ ), and change in the volume of organic component of mobile phase (by $\pm 10 \%$ absolute).

\section{Stability of analytical solution}

Stability of analytical solution was verified by analyzing standard solution and sample solution at different time intervals by storing then at room temperature. Results are given in Table 13.

Conclusion: The sample is stable up to $5 \mathrm{~h}$ and the standard is stable up to $6 \mathrm{~h}$ without protected from light at room temperature.

\section{CONCLUSION}

The method was validated as per the ICH requirements for specificity, linearity, accuracy (recovery), precision, robustness, stability of analytical solution, media degassing study, and filter study and results were found to meet the acceptance criteria. Hence, the validated method is specific, linear, accurate, precise, and robust for determination of dissolution of levonorgestrel tablets, this method can be used for the routine and stability analysis for the determination of 
the assay and content uniformity of levonorgestrel in levonorgestrel tablets.

\section{ACKNOWLEDGMENT}

We are grateful to our Director Dr. A. K. Rai Sir and Dean Dr. Pranay Wal Sir for their guidance and support as well as to the Department of Pharmacy, Pranveer Singh Institute of Technology, Kanpur, Uttar Pradesh, India.

\section{AUTHORS' CONTRIBUTIONS}

We declare that this work was done by the authors named in this article and all liabilities pertaining to claims relating to the content of this article will be borne by the authors. Mr. Vikas Kumar Pal has carried out the experiment and analyzed the data. Assistant Professor Yogendra Pal proof-read the whole manuscript, and suggested the necessary changes, and helped in designing the manuscript.

\section{CONFLICTS OF INTEREST}

The authors declare that there are no conflicts of interest regarding the publication of this paper.

\section{AUTHORS FUNDING}

No funding agency.

\section{REFERENCES}

1. Ahuja S, Dong M. Handbook of Pharmaceutical Analysis by HPLC. $1^{\text {st }}$ ed. Amsterdam: Elsevier; 2005

2. Snyder LR, Kirkland JJ, Glajch JL. Practical HPLC Method Development. $2^{\text {nd }}$ ed. Hoboken: John Wiley \& Sons, Inc.; 1997.
3. Ravindra A, Hima P, Swamy KN, Kumar KV. Validated RPHPLC method for simultaneous estimation of levonorgestrel and ethinylestradiol in combined dosage form. J Sci Innov Res 2013;2:642-50.

4. Basarabad CN, Westhoff CL, Pike MC, Nandkumar R, Cremers S. Estimating systemic exposure to levonorgestrel from an oral contraceptive. Contraception 2017;95:398-404.

5. Back DJ, Bates M, Breckenridge AM, Hall JM, MacIver M, Orme ML, et al. The pharmacokinetics of levonorgestrel and ethinylestradiol in women-studies with ovran and ovranette. Contraception 1981;23:229-39.

6. Fotherby K. Potency and pharmacokinetics of gestagens. Contraception 1990;41:533-50

7. Fotherby K. Pharmacokinetics of gestagens: Some problems. Am J Obstet Gynecol 1990;163:323-8.

8. Seifeldeen EM, Etman MA, Aboul-Enein HY. Simultaneous determination of four hormonal compounds in oral contraceptive tablet formulations by high performance liquid chromatography. Taylor Francis Online 2016;39:1-24.

9. Dasari P, Veerareddy A, Bhoomireddy R, Chvsl K, Bethi M. Development and validation of stability indicating RP-HPLC method for the determination of impurity profile in gamendazole: Experimental male oral contraceptive. J Liq Chromatogr Relat Technol 2015;38:37-41.

10. Charde MS, Welankiwar AS, Kumar J. Method development by liquid chromatography with validation. Int J Pharm Chem 2014;4:57-61.

11. Gupta V, Deep A, Jain K, Gill NS, Gupta K. Development and validation of HPLC method-a review. Int Res Pharm Appl Sci 2012;2:17-25.

12. Bhagyasree $\mathrm{T}$, Injeti N, Azhakesan A, Rao UM. A review on analytical method development and validation. Int J Pharm Res Anal 2014;4:444-8.

13. Chan CC, Leo YC, Lam H. Analytical Method Validation and Instrument Performance Verification. Vol. 1. USA: Wiley Interscience; 2004.

14. George N. Force degradation studies as an integral part of HPLC stability indicating assay method development. J Drug Deliv Technol 2010;10:1-4. 